\title{
Europe agrees to act for protection of the ozone layer
}

\section{London}

European environment ministers have agreed on the need for international action to control emissions of chlorofluorocarbons (CFCs) into the atmosphere. Under pressure from the United States and from environmental groups, the Council of Ministers of the European Economic Community (EEC) decided in Brussels on 19 March that they are ready to negotiate a global reduction of CFCs.

The EEC will thus attend the conference of the Vienna Convention on the Protection of the Ozone Layer at the end of April with a position in favour of a freeze on production of CFCs 11 and 12 at 1986 levels, a 20 per cent reduction in production of the same materials within five to seven years, a four-yearly scientific review of the evidence on CFCs and restrictions on imports from countries not signing the proposed protocol.

The United States supports a much stronger position, calling for a freeze on production followed by a 50 per cent reduction in five years and a 95 per cent reduction in $10-15$ years. The Soviet Union, Canada, West Germany, the Netherlands and the Scandinavian countries are also pushing for big reductions.

Studies by the US Environmental Protection Agency (E.PA) show that an 85 per cent cut would be needed just to stabilize current atmospheric concentrations.

Next month's negotiations are aimed at providing the details for a binding international protocol, which is expccted to be ready for signing in the autumn by the 28 signatories to the Vienna Convention.

Regulatory measures have been given an additional urgency by new evidence on the Antarctic ozone hole. The results from the ultraviolet spectrometer of the National Ozone Expedition to Antarctica indicate levels of chlorine dioxide $20-50$ times higher than those previously measured anywhere, and microwave radiometer measurements of nitrogen oxides and chlorine monoxide provide further support for a chemical explanation of the hole.

There is also a startling new report on the extent and pattern of global ozone depletion. Before a US House of Representatives subcommittec on 9 March, Don Heath, a NASA (National Acronautics and Space Administration) scicmtist, reported that observations from NASA's Nimbus 7 satellite indicate a global depletion of total column ozone ol several per cent between the mid-1970s and the early 1980 s. He also reported a pattern of ozone thinning varying with latitude, with much greater depletion at higher latitudes.

The Heath data are being scrutinized by a peer-review committee because they suggest latitudinally specific levels of depletion an order of magnitude greater than predicted by two-dimensional models. Such an analysis recently completed for the EPA by Ivar Isaksen of the University of Oslo indicates depletion levels of 0.5 per cent at $80^{\circ}$ south latitude, 0.4 per cent at $60^{\circ}$ south, 0.4 per cent at $20^{\circ}$ and $40^{\circ}$ north and 0.9 per cent at $80^{\circ}$ north. Heath's data suggest depletion up to ten times as much as these predictions.

Heath also told the subcommittee that his observations point to a second ozone hole over Spitzbergen in the Arctic, al though with less severe and extensive depletion than that over the Antarctic.

New information on the human health implications of ozone depletion was also presented to the US Congress earlier this month. Subcommittee members were told that recent analysis by the US government indicates that for every 1 per cent of globally averaged ozone depletion, there will be $10,000-20,000$ additional cases of skin cancer a year in the United States alone, with several hundred additional deaths.

Cancer experts say that people who live at $40^{\circ}$ latitude or above are considered more at risk for skin cancer, while fairskinned fair-haired people of celtic origin have been shown to be the most vulnerable to skin cancer induced by increased ultraviolet radiation.

\section{Another crisis for SERC and British researchers}

\section{London}

ThF Science and Engineering Research Council (SERC), the principal source of funds for British university rescarch, has

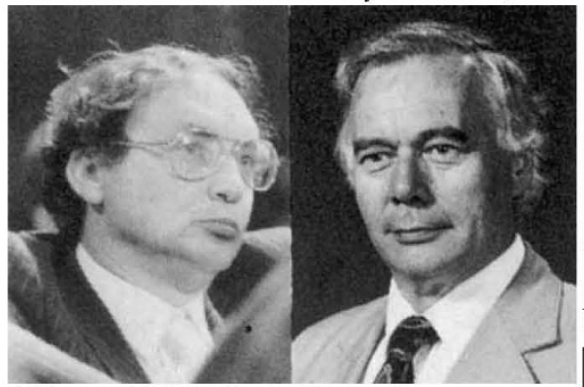

Akker and Mitchell - suffering from cuts

cancelled its next round of grant awards for lack of cash.

Professor E. W. J. Mitchell, chairman of SERC, had a private meeting last weck with the Secretary of State for Education and Science, Mr Kenneth Baker, to highlight the council's plight. The council's poor financial condition has been aggravated by last month's salary award to academic teaching staffs (see Nature 325, 567; 1987). The effect in a full year will be to increase SERC's financial commitments by $£ 10$ million a ycar on a budget (for research grants only) of $£ 100$ million.

The council has frozen some 1,500 applications for grants until September in the hope that the financial climate will have improved by then.

The ban and the meeting with Baker were the result of a review by the council last week. Commenting on the outcome. Mitchell said that the impact of the pay award on SERC's finances had bcen so great that, without extra funds from government, the council had "little alternative" but to cancel the April competition for research grants. Mitchell said that discussions with government are con- tinuing. SERC has, however, "reaffirmed its commitment to postgraduate education" by not reducing the planned number of studentships and fellowships.

John Akker, deputy general secretary of the AUT, says that SERC has "no option" but to take this action. Noting that the volume of civil research and development in the United Kingdom is already desperately low by international standards, Akker says that it is "crazy that our government is causing" the research councils to enforce cuts of this magnitude. According to the AUT, new research projects will now be stillborn and 500 research jobs sacrificed for lack of funds. "The government were party to the pay agreement which has given rise to the problems laced by SERC and the other research councils. The longer the government pro-

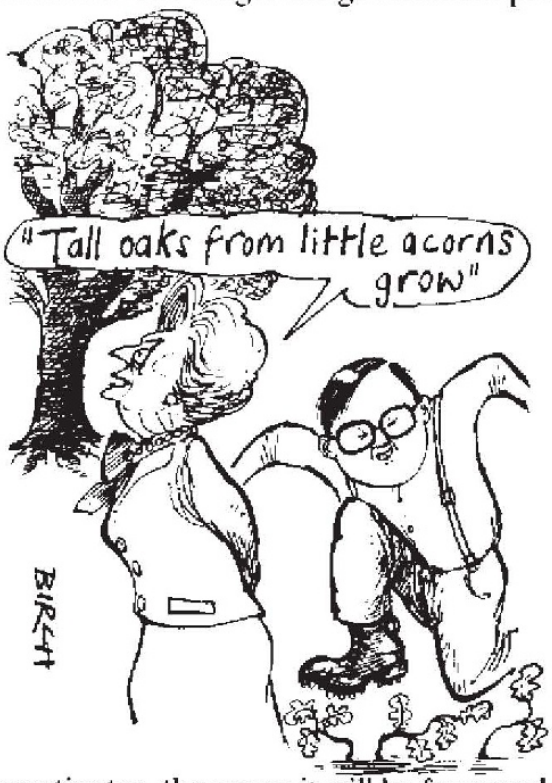

crastinates, the worse it will be for morale in the universities."

Bill Johnstone 